\title{
RELIABLE DISTURBANCE REJECTION
}

\author{
Pedro M. G. Ferreira
}

\author{
Departamento de Engenharia Elétrica \\ PUC-Rio \\ 22453-900 Rio de Janeiro, Brasil
}

Fax: (21) 2511-5645 pedro@reit.puc-rio.br Phone: (21) 2540-6915

\begin{abstract}
The paper studies the reliability (sensor and actuator failures) of the asymptotic disturbance rejection problem for linear time invariant systems using the factorization approach, assuming that not all loops fail simultaneously and that sensor and actuator do not fail simultaneously. The plant is two-output, i.e. two-vector-output, and the disturbance is at the measured output of the plant. Necessary and sufficient conditions are presented for the general problem and a simple solution is given for problems with stable plants.
\end{abstract}

KEYWORDS: Disturbance rejection; Actuator failures; Sensor failures; Stability.

\section{RESUMO}

Este artigo estuda o problema da confiabilidade - com falhas de sensores e atuadores - da rejeição assintótica de distúrbios em sistemas lineares multivariáveis invariantes no tempo usando o método da fatoração das matrizes de transferência. Supõe-se que não ocorram falhas simultâneas de todas as malhas de realimentação e que não haja falha simultânea de algum sensor e atuador. A planta tem dois vetores de resposta e o distúrbio ocorre na resposta que é medida. Obtêm-se condições necessárias e suficientes para o problema geral e uma solução simples é dada quando a planta é estável.

Artigo Submetido em 13/08/02

1a. Revisão em 10/06/03

2a. Revisão em 06/02/04

3a. Revisão em 30/09/04

Aceito sob recomendação do Ed. Assoc.Liu Hsu
PALAVRAS-CHAVE: Rejeição de distúrbios; Falhas nos atuadores; Falhas nos sensores; Estabilidade.

\section{INTRODUCTION}

A system is reliable if it can tolerate failures of actuators and / or sensors, while retaining desired control system properties.

The reliability problem has been studied, among others, by Ackerman (1985) and Siljak (1980), who addressed the stability problem, by Date \& Chow (1989), who studied the pole placement problem. The reliable stability problem is addressed also with the name of integrity or partial integrity: see Fujita \& Shimemura (1988), Desoer \& Gündes (1988b) and Ferreira (1990). The reliable stability with integral controller was addressed by Morari (1985) and by Gündes \& Kabuli (2001). The reliable servo system problem has been addressed in Ferreira (2001) and the tracking problem with sensor failures has been recently addressed in Ferreira (2002).

In this paper, we address the reliable asymptotic rejection of disturbances at the measured output of the plant with sensor and actuator failures. Besides the solutions in the general cases corresponding to sensor and actuator failures, a simple solution is given when the plant is stable. An example illustrates the issues. We handle the continuous time problem, but the results are algebraic, so they can be easily adapted for discrete time systems.

\section{Notation:}

The set of proper and stable rational functions, a principle ideal domain (Vidyasagar, 1985), is denoted by S. The set of matrices with elements in $\mathbf{S}$ is denoted by $\mathbf{M}(\mathbf{S})$. $\mathbf{U}(\mathbf{S})$ will denote the set of all unimodular matrices in $\mathbf{M}(\mathbf{S})$. 


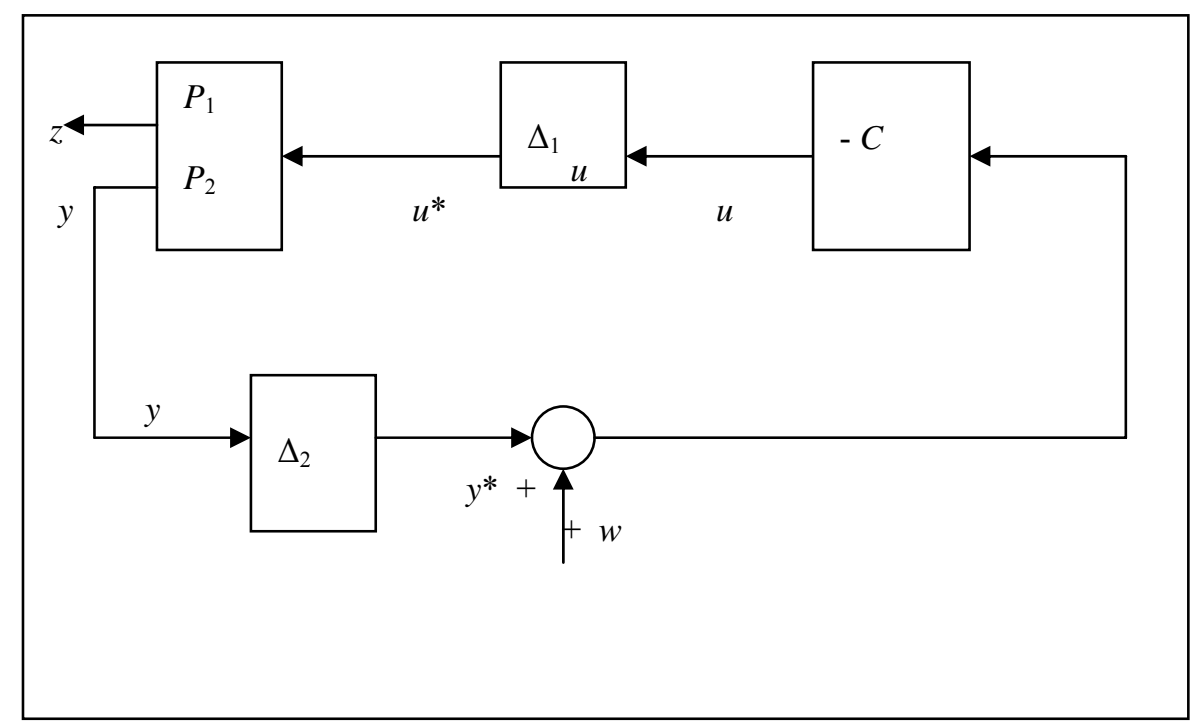

In the block diagram below the inputs and outputs are Laplace-transforms of multivariable signals. $w(s)$ is the Laplace transform of the signal to be asymptotically rejected at the inverse Laplace-transform of $z(s)$.

$$
P(s)=\left[\begin{array}{c}
P_{1}(s) \\
P_{2}(s)
\end{array}\right] \text { represents the given plant. }
$$

$C(s)$ is the compensator to be designed.

$$
\Delta_{1}=\operatorname{diag}\left(\delta_{11}, \delta_{12}, \ldots, \delta_{1 \mathrm{~m}}\right)
$$

$\Delta_{2}=\operatorname{diag}\left(\delta_{21}, \delta_{22}, \ldots ., \delta_{2 \mathrm{p}}\right), \quad \delta_{\mathrm{ij}}=1$ or 0 , but neither all $\delta_{1 \mathrm{j}}$ nor all $\delta_{2 \mathrm{j}}$ are zero. all $\mathrm{j}$.

Besides, if some $\delta_{1 \mathrm{k}}\left(\delta_{2 \mathrm{k}}\right)=0$, then $\delta_{2 \mathrm{j}}\left(\delta_{1 \mathrm{j}}\right)=1$ for

We say that the solution of the asymptotic disturbance rejection problem is reliable with respect to actuator (sensor) failures if it is achieved for all allowed $\Delta_{1}\left(\Delta_{2}\right)$.

We will omit the argument (s) when convenient.

$P_{1}, \quad P_{2}$ and $C$ are proper rational matrices and have the appropriate dimensions.

The exogenous signal $w$ is assumed proper.

Let $P=\left\lceil\begin{array}{l}P_{1} \\ P_{2}\end{array}\right\rceil=\left\lceil\begin{array}{l}N_{1} \\ N_{2}\end{array}\right\rceil D^{-1}$, a right coprime factorization.

All the factorizations of the paper will be over $\mathbf{M}(\mathbf{S})$.

Let $C=D_{l c}{ }^{-1} N_{l c}$ define a left coprime factorization of the compensator. (The factors of left coprime factorizations will always have a subscript " " " ). Define $C=N_{\mathrm{c}} D_{\mathrm{c}}^{-1}$, $P_{2}=D_{l}^{-1} N_{l 2}$, right coprime and left coprime factorizations, respectively.

Define $\quad w=D_{l \mathrm{w}}{ }^{-1} N_{l \mathrm{w}} w_{0}$, where $D_{l \mathrm{w}}$ is a known matrix, $N_{l \mathrm{w}}$ need not be known, $D_{l \mathrm{w}}$ and $N_{l \mathrm{w}}$ are left coprime and $w_{0}$ is an arbitrary vector of real numbers.

We use the standard definition of closed loop stability. Notice that the closed loop is stable only if $N_{2}$ and D are right coprime: see for example Desoer and Gündes (1988a). It is known that the closed loop is stable if and only if (see Vidyasagar (1985)):

$D_{l \mathrm{c}} D+N_{l \mathrm{c}} N_{2}=I$

$D_{l} D_{\mathrm{c}}+N_{l 2} N_{\mathrm{c}}=I$

On the other hand, asymptotic rejection is achieved when $z(s)$ has no pole in the closed right plane.

\section{THE RESULTS}

Consider sensor outages, provided that not all sensors fail simultaneously. Denote by $y^{*}$ the failed measured output. Define $P_{2 \mathrm{r}}$ and $N_{2 \mathrm{r}}$ correspondingly, i.e., with zero rows corresponding to the zero elements of $\mathrm{y}^{*}$. It is clear that $y^{*}$ $=P_{2 \mathrm{r}} u=N_{2 \mathrm{r}} D^{-1} u$. Let $\mathbf{P}_{\mathbf{r}}$ and $\mathbf{N}_{\mathbf{r}}$ denote the set of all allowed $P_{2 \mathrm{r}}$ 's and $N_{2 \mathrm{r}}$ 's, respectively. It is clear, according to the assumption, that the zero matrix does not belong to $\mathbf{P}_{\mathbf{r}}$ and $\mathbf{N}_{\mathbf{r}}$. 
Lemma 1: Asymptotic rejection of $w$ is reliable with respect to sensor failures if and only if the nominal closed loop is stable and

i) $\quad I-N_{l \mathrm{c}}\left(N_{2}-N_{2 \mathrm{r}}\right) \in \mathbf{U}(\mathbf{S}) \quad \forall N_{2 \mathrm{r}} \in \mathbf{N}_{\mathbf{r}}$

ii) $\quad N_{1}\left[I-N_{l \mathrm{c}}\left(N_{2}-N_{2 \mathrm{r}}\right)\right]^{-1} N_{l \mathrm{c}} \quad D_{l \mathrm{w}}{ }^{-1} \in \mathbf{M}(\mathbf{S}) \forall N_{2 \mathrm{r}}$ $\in \mathbf{N}_{\mathbf{r}}$.

Proof: (We give a proof for completeness, it has appeared in a less general set-up in Ferreira (2001)).

Notice that if the nominal loop is stable, we have, in view of (1),

$D_{l \mathrm{c}} D+N_{l \mathrm{c}} N_{2 \mathrm{r}}=I-N_{l \mathrm{c}}\left(N_{2}-N_{2 \mathrm{r}}\right)$,

which implies the necessity of i), and notice that this condition implies the right coprimeness of $N_{2} \mathrm{r}$ and $D$. Next,

$u=-C\left(w+y^{*}\right)=-\left(I+C P_{2 \mathrm{r}}\right)^{-1} C \mathrm{w}=-D\left[I-N_{l \mathrm{c}}\left(N_{2}\right.\right.$ $-N_{2 \mathrm{r}}$ ) $]^{-1} N_{l \mathrm{c}} w$, in view of (3),

$Z=P_{1} u=-N_{1}\left[I-N_{l \mathrm{c}}\left(N_{2}-N_{2 \mathrm{r}}\right)\right]^{-1} N_{l \mathrm{c}} D_{l \mathrm{w}}{ }^{-1} N_{l \mathrm{w}} w_{0}$ $\in \mathbf{M}(\mathbf{S}) \forall N_{2 \mathrm{r}} \in \mathbf{N}_{\mathbf{r}}$.

Hence asymptotic rejection of $w$ implies ii).

On the other hand, it is clear that loop nominally stable and satisfaction of conditions i) and ii) imply asymptotic disturbance rejection in the nominal situation and with failed loops, completing the proof.

We consider next actuator failures. Again, it is assumed that not all loops fail simultaneously. When actuator failures occur, the input to the plant will be $u^{*}$. The measured output will be $P_{2} u^{*}=: P_{2 \mathrm{f}} u$, where $P_{2 \mathrm{f}}$ is defined in the obvious way, i.e., with zero columns corresponding to the zero elements of $u^{*}$. Analogously, the controlled output will be $P_{1 \mathrm{f}} u$. Let $P_{2 \mathrm{f}}=: D_{l}^{-1} N_{l 2 \mathrm{f}}$. The set of all allowed $P_{2 \mathrm{f}}$ 's and $N_{l 2 \mathrm{f}}$ 's $\mathrm{s}$ will be denoted by $\mathbf{P}_{\mathrm{f}}$ and $\mathbf{N}_{\mathbf{f}}$, respectively. It is clear that it is assumed that the zero matrix does not belong to $\mathbf{P}_{\mathbf{f}}$ and $\mathbf{N}_{\mathbf{f}}$.

We have then

Lemma 2: Asymptotic rejection of $w$ is reliable with respect to failures in the actuator if and only if the nominal loop is stable and

i) $I-\left(N_{l 2}-N_{l 2 \mathrm{f}}\right) N_{\mathrm{c}} \in \mathbf{U}(\mathbf{S}) \forall N_{l 2 \mathrm{f}} \in \mathbf{N}_{\mathrm{f}}$

ii) $P_{1 \mathrm{f}} N_{\mathrm{c}}\left(I-\left(N_{l 2}-N_{l 2 \mathrm{f}}\right) N_{\mathrm{c}}\right)^{-1} D_{l} D_{l \mathrm{w}}{ }^{-1} \in \mathbf{M}(\mathbf{S}) \forall N_{l 2 \mathrm{f}}$ $\in \mathbf{N}_{\mathbf{f}}$.

Proof: (A proof in a less general set-up was given in Ferreira (2001).
Condition i) follows from (2), analogously as in the first lemma. Next,

$$
\begin{aligned}
z & =P_{1 \mathrm{f}} u=-P_{1 \mathrm{f}} C\left(I+P_{2 \mathrm{f}} C\right)^{-1} w \\
& =-P_{1 \mathrm{f}} N_{\mathrm{c}}\left(D_{l} D_{\mathrm{c}}+N_{l 2 \mathrm{f}} N_{\mathrm{c}}\right)^{-1} D_{l} D_{l \mathrm{w}}{ }^{-1} N_{l \mathrm{w}} w_{0} \\
& =-P_{1 \mathrm{f}} N_{\mathrm{c}}\left(I-\left(N_{l 2}-N_{l 2 \mathrm{f}}\right) N_{\mathrm{c}}\right)^{-1} D_{l} D_{l \mathrm{w}}{ }^{-1} N_{l \mathrm{w}} w_{0}
\end{aligned}
$$

from which follows ii).

On the other hand, it is clear that loop nominally stable and satisfaction of conditions i) and ii) imply asymptotic disturbance rejection in the nominal situation and with failed loops, completing the proof.

The conditions of the two lemmas, especially the second, are neither much insightful nor practical from a calculation point of view. But with stable plants, we get a very practical result, as shown in the proof of the following result, in which we assume that actuator and sensor do not fail simultaneously. The proof of the sufficiency will be constructive.

Theorem: Assume that the plant is stable. Then the asymptotic rejection of $w$ with sensor (actuator) failures is possible if and only if it is possible without failures

Proof: Necessity is obvious.

For sufficiency, according to the Youla-Bongiorno-Kucera parameterization, any $C$ which stabilizes in the feedback loop a stable $P_{2}$ is given by the coprime factorizations

$C=\left(I-N_{\mathrm{c}} P_{2}\right)^{-1} N_{\mathrm{c}}=N_{\mathrm{c}}\left(I-P_{2} N_{\mathrm{c}}\right)^{-1}$,

$N_{\mathrm{c}}$ arbitrary but such that $\operatorname{det}\left(I-N_{\mathrm{c}} P_{2}\right) \neq 0$. (Notice that $N_{l \mathrm{c}}=N_{\mathrm{c}}$ ).

In the case of sensor failure, condition i) of Lemma 1 is

$I-N_{\mathrm{c}}\left(P_{2}-P_{2 \mathrm{r}}\right) \in \mathbf{U}(\mathbf{S}) \quad \forall P_{2 \mathrm{r}} \in \mathbf{P}_{\mathbf{r}}$,

while condition ii) of the same Lemma is

$P_{1}\left[I-N_{\mathrm{c}}\left(P_{2}-P_{2 \mathrm{r}}\right)\right]^{-1} N_{\mathrm{c}} D_{l \mathrm{w}}{ }^{-1} \in \mathbf{M}(\mathbf{S}) \forall P_{2 \mathrm{r}} \in \mathbf{P}_{\mathbf{r}}$. (5)

Choose $\quad N_{\mathrm{c}}$ such that $N_{\mathrm{c}} D_{l \mathrm{w}}{ }^{-1} \in \mathbf{M}(\mathbf{S}), \quad\left\|N_{\mathrm{c}}\right\|$ sufficiently small so that

$\left\|N_{\mathrm{c}}\left(P_{2}-P_{2 \mathrm{r}}\right)\right\|<1$

It is clear that with this choice, (4) and (5) are satisfied.

In the case of actuator failures, conditions i) and ii) of Lemma 2 are

$I-\left(P_{2}-P_{2 \mathrm{f}}\right) N_{\mathrm{c}} \in \mathbf{U}(\mathbf{S}) \quad \forall P_{2 \mathrm{f}} \in \mathbf{P}_{\mathrm{f}}$

and

$P_{1 \mathrm{f}} N_{\mathrm{c}}\left(I-\left(P_{2}-P_{2 \mathrm{f}}\right) N_{\mathrm{c}}\right)^{-1} D_{l \mathrm{w}}{ }^{-1} \in \mathbf{M}(\mathbf{S}) \forall P_{2 \mathrm{f}} \in \mathbf{P}_{\mathrm{f}}$, respectively.

This last is equivalent to 
$P_{1 \mathrm{f}}\left(I-N_{\mathrm{c}}\left(P_{2}-P_{2 \mathrm{f}}\right)\right)^{-1} N_{\mathrm{c}} D_{l \mathrm{w}}{ }^{-1} \in \mathbf{M}(\mathbf{S}) \forall P_{2 \mathrm{f}} \in \mathbf{P}_{\mathrm{f}}$.

Choose $N_{\mathrm{c}}$ such that $N_{\mathrm{c}} D_{l \text { w }}{ }^{-1} \in \mathbf{M}(\mathbf{S}),\left\|N_{\mathrm{c}}\right\|$ sufficiently small so that $\| N_{\mathrm{c}}$ $\left(P_{2}-P_{2}\right.$ f $) \|<1$, so (7) and (8) are satisfied. This completes the proof.

\section{CONCLUSION}

The paper studies the reliable asymptotic disturbance rejection problem with sensor and actuator failures with two-output plant and the disturbance entering the loop at the measured plant's output. We use the factorization approach a la Vidysagar (1985) and establish the necessary and sufficient conditions for both the sensor and actuator problems in the general case (unstable plant). When the plant is stable, a sufficient condition is obtained, the same compensator solving both the sensor and actuator problems (but nos simultaneously).

\section{REFERENCES}

Ackermann, J. (1985). Sampled-Data Control Systems. Springer Verlag, New York.

Date, R. A. \& Chow, J. H. (1989). A reliable coordinated decentralized control system design. Proc. $28^{\text {th }}$. Confer. Decision and Control, pp. 1295-1300. Tampa, FL.

Desoer, C. A. \& Gündes, A. N. (1988a). Algebraic theory of linear time-invariant feedback systems with twoinput two-outpu plant and compensator. International Journal of Control, vol. 47, pp. 33-51.

Desoer, C. A. \& Gündes, A. N. (1988b). Stability under sensor or actuator failure. Proc. $27^{\text {th }}$. Confer. on Decis. and Control, pp. 2148-2149. Austin, Texas.

Ferreira, Pedro M. G. (1990). Partial integrity. Intern. Journal of Control, vol 52, pp. 509-515.

Ferreira, Pedro M. G. (2001). On the reliable servo system. Proc. of the American Control Conference, pp. 1021-1025. Arlington, Virginia.

Ferreira, Pedro M. G. (2002). Tracking with sensor failures. Automatica, vol. 38, pp.1621-1623.

Fujita, M. \& Shimemura, E. (1988). Integrity against arbitrary feedback-loop failure in linear multivariable control systems. Automatica, vol. 24, pp. 765-772.

Gündes, A. N. \& Kabuli, M. G. (2001). Reliable decentralized integral - action controller design. IEEE Trans. on Autom. Control, vol. 46, pp. 296-301.
Morari, M. (1985). Robust stability of systems with integral controllers. IEEE Trans. on Autom. Control, vol. AC-30, pp. 574-577.

Siljak, D. D. (1980). Reliable control using multiple control systems. Intern. Journal of Control, vol. 31, pp. 303-329.

Vidyasagar, M. (1985). Control System Synthesis: A Factorization Approach. MIT Press, Cambridge, MA. 